\title{
Burden and happiness in head and neck cancer carers: the role of supportive care needs
}

\author{
Paul Hanly ${ }^{1}$ - Rebecca Maguire ${ }^{1} \cdot$ Myles Balfe $^{2} \cdot$ Philip Hyland $^{1} \cdot$ Aileen Timmons $^{2}$. \\ Eleanor O'Sullivan ${ }^{3} \cdot$ Phyllis Butow $^{4} \cdot$ Linda Sharp ${ }^{5}$
}

Received: 13 January 2016 / Accepted: 3 May 2016 / Published online: 16 May 2016

(C) Springer-Verlag Berlin Heidelberg 2016

\begin{abstract}
Purpose Our study aimed to investigate the relationship between unmet supportive care needs and carer burden and happiness, in head and neck cancer (HNC).

Methods Two hundred eighty-five HNC informal carers were sent a postal questionnaire between January and June 2014, which included the supportive care needs survey for partners and caregivers of cancer survivors (SCNS-P\&C) and the CarerQol, which assesses burden and happiness. Multiple regression analysis was conducted to examine the association of (i) carer characteristics, (ii) carer situation, and (iii) unmet supportive care needs, with carer burden and happiness Results One hundred ninety-seven carers completed the questionnaire (response rate $=69 \%$ ), 180 of whom were included in the analysis. The majority were female (76\%), not in paid employment (68\%) and caring for their spouse $(67 \%)$. On average, carers reported relatively low levels of burden and relatively high levels of happiness. Carer factors explained $42 \%$ of variance in levels of burden and $24 \%$ of variance in levels of happiness. Healthcare service needs were associated with carer burden $(\beta=.28, p=.04)$, while psychological needs $(\beta=-.38, p=.028)$, health care service needs $(\beta=-.30$, $p=.049)$, information needs $(\beta=.29, p=.028)$, carer
\end{abstract}

Paul Hanly

paul.hanly@ncirl.ie

\footnotetext{
National College of Ireland, Mayor Street, Dublin 1, Ireland

National Cancer Registry Ireland, Cork, Ireland

University College Cork, Cork, Ireland

University of Sydney, Sydney, Australia

Newcastle University, Newcastle upon Tyne, UK
}

comorbidity $(\beta=-.18, p=.030)$, and gender $(\beta=-.16$, $p=.045)$ were associated with happiness.

Conclusions Our results indicate that different aspects of carer characteristics and unmet needs are associated with carer burden and happiness. Efforts directed at reducing unmet healthcare service needs in particular are merited given their associations with both aspects of carer quality of life.

Keywords Unmet needs - Carer burden - Quality of life . Head and neck cancer carer burden $\cdot$ Happiness

\section{Background}

Head and neck cancer (HNC) is a composite term for cancers arising in the oral cavity, oropharynx, and larynx [1]. Globally, HNC accounts for approximately 550,000 cases annually [2], with incidence rates rising in many countries, particularly in younger individuals, and mortality rates falling in developed countries [1]. These trends, combined with an increased role for out-patient and community care, have resulted in a rise in the importance of informal care for HNC survivors [3].

Informal carers of $\mathrm{HNC}$ survivors, and cancer survivors more generally, play a crucial role helping them deal with functional, clinical, and psychosocial issues resulting from the disease, and its treatment [3-5]. The burden of those caring activities can result in the emergence of significant unmet supportive care needs $[5,6]$. These needs range from informational, communication, psychosocial, emotional, financial, medical, and spiritual [6-10], and are often not adequately met by health professionals [9].

Previous studies have indicated that unmet supportive care needs impose significant burdens on cancer carers, impacting on their health and quality of life [5, 6, 9, 11-13]. Specifically, unmet needs have been found to be associated with poor carer 
mental health [6, 14], distress [14], anxiety [9], depression [8], and fatigue [7] in cancer carer populations. In the case of $\mathrm{HNC}$, Chen et al. [15] revealed that HNC patients experience relatively high supportive care needs, especially with regard to information needs, and that these were associated with higher carer burden. A further study [12] found that HNC carers' unmet care needs were associated with depression, although the findings were not statistically significant.

Despite the increasing body of evidence on cancer carers' unmet supportive care needs and their negative impact on carers' quality of life, few studies have considered both positive and negative aspects of carer quality of life and what predicts these. The literature indicates that carer quality of life is affected in a multidimensional manner [16-18]. The CarerQol instrument measures perceived carer burden in two positive and five negative dimensions, and measures general happiness using a single visual analogue scale (VAS), the latter increasingly recognised as a core component of quality of life [19]. This measure provides a comprehensive description of the carer experience and allows the current study to examine carer burden and quality of life in a multidimensional context.

A literature gap exists with regard to whether there is a link between HNC carers' supportive care needs and different elements of carer quality of life including burden and happiness. Our study aimed to investigate unmet supportive care needs in predicting carer burden and happiness as measured by the CarerQol, in HNC, while controlling for the influence of carer characteristics and aspects of the care situation.

\section{Methods}

\section{Participants}

This study was part of a larger project that investigated the post-treatment experiences of $\mathrm{HNC}$ survivors and their carers in Ireland $[20,21]$. The study was survey-based, cross sectional in design, and descriptive and correlational in nature.

In total, $583 \mathrm{HNC}$ survivors, sampled from the National Cancer Registry Ireland, completed a postal survey. Details of this survey and the demographics of the survivor sample have been published previously [21] and included a majority of older males (67\% male, mean age 63 ) with a substantial minority living in difficult financial circumstances prior to diagnosis $(30 \%)$. Respondents were asked for permission to contact their carer if they had one (defined as a family member, friend or another person who had been helping take care of them since their diagnosis). Carer inclusion criteria for this study included being (a) designated as the primary caregiver by the survivor and (b) caring for their relative/friend for one or more years post diagnosis. We wrote to 285 carers matching these criteria between January and June 2014, providing them with information about the study, and sent out a questionnaire 2 weeks after the initial contact letter. When carers returned their questionnaire, they also provided written consent to take part in the study. Nine Irish university hospital ethics committees, covering a range of hospitals across the country, provided ethical approval for the project.

\section{Instruments}

\section{Carer characteristics}

The questionnaire collected information on the carer's sociodemographic characteristics, including their gender, age, and employment status. Carers indicated whether they had any pre-existing (at the time of the cancer diagnosis) health conditions, specifically heart problems, stroke, lung problems, diabetes, mental health problems, cancer, or other conditions. Participants who indicated one or more of these conditions were classified as having a comorbid condition.

\section{Carer situation}

Carers were asked to indicate their relationship to the survivor, as well as whether caring had any impact on their financial situation. Following Sharp et al. [22], participants were asked to indicate the extent to which caring had made it more or less difficult for their household to make ends meet on a 7-point Likert type scale, ranging from 'much more difficult' (scored 1) to 'much less difficult' (scored 7). Scores were reversecoded so a higher score indicated higher levels of financial stress. Time allocated to caring was assessed by asking carers to estimate the typical amount of hours spent caring per week during the past month following Hanly et al. [23]. This included estimates of extra time spent on domestic activities such as cleaning and food preparation; activities of daily living (ADL) including assisting the survivor with personal care, eating, and drinking; instrumental activities of daily living (IADL) such as moving around, health care contacts, organising help and taking care of financial matters; and cancer-specific care. The total amount of time spent caring per week was computed by summing together the estimated hours in each domain.

\section{Carer unmet needs}

The perceived unmet supportive care needs of carers were assessed using the supportive care needs survey for partners and caregivers of cancer survivors (SCNS-P\&C) [24]. This is a 45-item measure which assesses four specific domains of unmet needs: (i) information needs, (ii) healthcare service needs, (iii) work and social needs, and (iv) psychological and emotional needs. Participants were asked to indicate whether they had no need (scored 0), a low need (1), a 
moderate need (2), or a high need (3) for each item. Following Chen et al. [12], we computed a standardised score ranging from 0 to 100 for each of the four domains, and a total standardised score. This instrument has demonstrated good reliability and validity previously $[12,24,25]$ and had a Cronbach's alpha in our sample of .97 .

\section{CarerQoL}

The CarerQol was used to assess subjective carer burden and happiness. This instrument was based on the EuroQol instrument measuring health-related quality of life and highlights connections between carer burden and quality of life which was deemed appropriate for this study. It was designed by Brouwer et al. [26] to provide, among other things, a comprehensive description of the caregiving situation. While not specific to any given carer situation, this generic instrument facilitates comparisons of the effects of caring on different population groups of carers which adds to the generalisability of the derived findings in this study.

The CarerQol comprises two separate measures. The first (CarerQol-7D) is a descriptive system consisting of five negative burden 'dimensions' (mental health, physical health, financial problems, relational problems, problems with daily activities) and two positive 'dimensions' (fulfilment and support). Each dimension consists of a single item statement that has three response categories: no (1), some (2), and a lot (3), which potentially distinguish 2187 discrete care situations. After reverse coding positive items, we summed participants' responses to calculate a total burden score which was then standardised to $0-100$. The CarerQol-7D had a Cronbach's alpha in our sample of .62.

The second measure (CarerQol-VAS) is a horizontal visual analogue scale that measures the wellbeing of carers in terms of general happiness. Scale endpoints range from 'completely unhappy' (0) to 'completely happy' (10). This type of broad outcome measure incorporates the disparate effects associated with informal care in the valuation process, including, for example, health effects and financial effects [27]. The ability of the CarerQol to measure the impact of caring is supported by a growing number of construct validation studies in adult carer populations where the instrument exhibited good clinical and convergent validity [26, 28-30]. Studies have demonstrated that it is a clear, easy to use, and comprehensible instrument [26].

\section{Statistical analysis}

Standard multiple regression analysis was conducted to determine the effect of predictor variables (categorised by (i) carer characteristics, (ii) carer situation, and (iii) carer support and information needs) on two outcomes: carer burden and carer happiness. Bivariate correlations were conducted prior to the regression using Pearson product-moment correlation coefficients to determine the relationship between the predictor variables and the two outcome variables, and to ensure no violation of the assumption of multicollinearity. Correlations were below the recommended criteria for determining violation of the assumption of multicollinearity [31]. Additional tests indicated no violations of the assumptions of normality, linearity, and homoscedasticity. Both models contained all potential predictor variables and associations were considered statistically significant at the $5 \%$ level (two-sided tests).

\section{Results}

\section{Carer characteristics and care situation}

A total of 197 carers completed the questionnaire yielding a response rate of $69 \%$. For the purposes of this study, 180 respondents were included, with 17 respondents excluded due to legal, ethical and data protection reasons.

Table 1 displays frequency data for the available variables in the sample. The majority of carers were female (76\%), not in paid employment $(68 \%)$ and had no comorbid conditions (53\%). Carers' age ranged from 23 to 85 years, with a mean of $57.3(\mathrm{SD}=12.5)$. Two thirds were caring for their spouse (67\%). On average, carers reported a negative impact of caring on their finances (mean financial stress $=4.7 ; \mathrm{SD}=1.2$ ) and spent $9.5 \mathrm{~h}$ a week caring for the HNC survivor, although this varied considerably with some carers experiencing a considerable time burden of up to $112 \mathrm{~h}$ per week $(\mathrm{SD}=18.4$, range: $0-112)$.

\section{Supportive care needs}

While overall reported unmet needs were generally low (mean $=10.6$ ), the highest ranking unmet need domain was psychological and emotional needs (14.44), followed by healthcare service needs (13.01), information needs (11.93), and work and social needs (9.57). Over half (51.4\%) of carers reported at least one moderate/high unmet need.

\section{Carer burden and happiness}

Generally, carers reported low levels of burden (mean $=23.2$; $\mathrm{SD}=16.6)$ and high levels of happiness (mean $=7.5$; $\mathrm{SD}=2.1)($ Table 1). Figure 1 provides responses to the individual CarerQol dimensions. Almost all HNC carers experienced some or a lot of fulfilment caring $(94 \%)$, while almost 
Table 1 Frequencies and descriptive statistics for categorical and continuous variables of HNC carers

\begin{tabular}{|c|c|c|c|c|c|}
\hline Variable & Frequency & Valid \% & - & - & - \\
\hline \multicolumn{6}{|l|}{ Categorical variables } \\
\hline \multicolumn{6}{|l|}{ Gender } \\
\hline Male & 43 & 24 & & & \\
\hline Female & 136 & 76 & & & \\
\hline \multicolumn{6}{|l|}{ Employment Status } \\
\hline Employed & 58 & 32 & & & \\
\hline Other & 122 & 68 & & & \\
\hline \multicolumn{6}{|l|}{ Comorbidity } \\
\hline No comorbid medical condition & 85 & 57 & & & \\
\hline At least one comorbid medical condition & 63 & 43 & & & \\
\hline \multicolumn{6}{|l|}{ Relationship to Patient } \\
\hline Spouse & 122 & 68 & & & \\
\hline Other & 58 & 32 & & & \\
\hline Continuous variables & M & SE & $95 \%$ Confidence interval & Range & Possible range \\
\hline \multicolumn{6}{|l|}{ Outcome variables } \\
\hline Burden & 23.23 & 1.30 & $20.66-25.79$ & $0-93$ & $0-100$ \\
\hline Happiness & 7.51 & 0.16 & $7.19-7.83$ & $0-10$ & $0-10$ \\
\hline \multicolumn{6}{|l|}{ Explanatory variables } \\
\hline Time for caring (hours) & 9.53 & 1.37 & $6.3-12.24$ & $0-112$ & $0-112$ \\
\hline Financial impact & 4.66 & 0.09 & $4.49-4.83$ & $1-7$ & $1-7$ \\
\hline Overall needs & 10.57 & 1.44 & $7.71-13.42$ & $0-97$ & $0-100$ \\
\hline Information needs & 11.93 & 1.50 & $8.97-14.88$ & $0-100$ & $0-100$ \\
\hline Health care needs & 13.02 & 1.49 & $10.08-15.95$ & $0-91$ & $0-100$ \\
\hline Work and social needs & 9.57 & 1.34 & $6.93-12.20$ & $0-100$ & $0-100$ \\
\hline Psychological needs & 14.44 & 1.67 & $11.14-17.74$ & $14-100$ & $0-100$ \\
\hline
\end{tabular}

three-quarters (72\%) also received support with their caring tasks. However, almost half of carers reported experiencing physical and/or mental health problems (44\%). Almost one in three carers indicated financial problems due to caring $(29 \%)$ while problems combining care tasks with daily activities (24\%) and relationship problems $(22 \%)$ were also evident.

\section{Multiple regression analysis}

When the carer characteristics, situation, and unmet needs variables were fitted, the model of carer burden was statistically significant $(F(11,121)=9.82, p<.001)$ and explained approximately $42 \%$ of variance in levels of burden (Table 2 ).

Figure 1 Distribution of response to CarerQol-7D dimensions for $\mathrm{HNC}$ carers
Problems physical health

\section{Support with tasks \\ Financial problems}

Problems combining tasks

Mental health problems

Relationship problems

Fulfilment with tasks

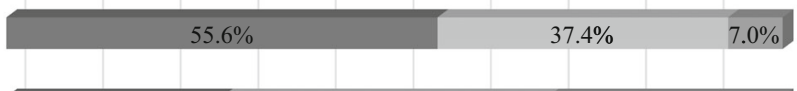

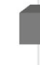

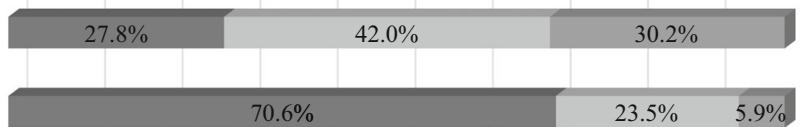

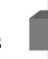

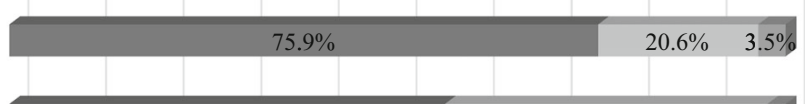

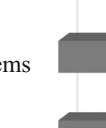
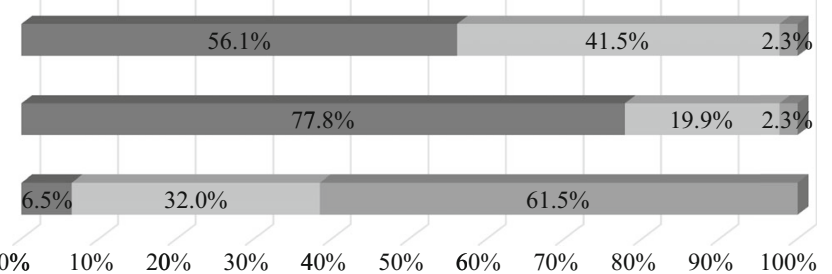
No Some A lot of 
Table 2 Multiple regression model for carer subjective burden (CarerQol-7D)

\begin{tabular}{|c|c|c|c|c|c|c|c|c|c|}
\hline & $R^{2}$ & Adjusted $R^{2}$ & $\beta$ & $p$ & $t$ & $B$ & SE & CI $95 \%$ (B) & \\
\hline Model $^{\mathrm{a}}$ & $.472 * *$ & $.424 * *$ & & & & & & & \\
\hline $\begin{array}{l}\text { Gender } \\
\quad \text { (Ref }^{\text {b: }} \text { Male) }\end{array}$ & & & 0.12 & .094 & 1.69 & 4.47 & 2.65 & -0.78 & 9.71 \\
\hline Age & & & 0.03 & .729 & 0.35 & 0.04 & 0.11 & -0.19 & 0.26 \\
\hline $\begin{array}{l}\text { Employment status } \\
\text { (Ref: Employed) }\end{array}$ & & & 0.04 & .576 & 0.56 & 1.49 & 2.65 & -3.76 & 6.73 \\
\hline $\begin{array}{l}\text { Comorbidity } \\
\text { (Ref: No medical condition) }\end{array}$ & & & 0.13 & .089 & 1.71 & 4.23 & 2.47 & -0.66 & 9.12 \\
\hline $\begin{array}{l}\text { Relationship } \\
\text { (Ref: Married/living with) }\end{array}$ & & & -0.06 & .461 & -0.74 & -2.08 & 2.82 & -7.67 & 3.50 \\
\hline Financial impact & & & 0.13 & .091 & 1.70 & 1.85 & 1.09 & -0.30 & 4.01 \\
\hline Time spent caring & & & 0.01 & .946 & -0.07 & 0.00 & 0.05 & -0.09 & 0.09 \\
\hline Information needs & & & -0.17 & .132 & -1.52 & -0.14 & 0.10 & -0.33 & 0.04 \\
\hline Health care needs & & & $0.28 *$ & .041 & 2.06 & 0.23 & 0.11 & 0.01 & 0.46 \\
\hline Work and social needs & & & 0.20 & .191 & 1.31 & 0.19 & 0.14 & 0.10 & 0.47 \\
\hline Psychological needs & & & 0.28 & .069 & 1.84 & 0.21 & 0.11 & -0.02 & 0.44 \\
\hline
\end{tabular}

Statistical significance: ${ }^{* *} p<.001,{ }^{*} p<.05$

${ }^{\text {a }}$ For all continuous variables, higher scores indicate higher levels of the variable

${ }^{\mathrm{b}}$ Reference category for categorical variables

Only unmet healthcare service needs was significantly positively associated with carer burden $(\beta=.28, p=.04)$.

The model of carer happiness was statistically significant $(\mathrm{F}(11,128)=4.95, p<.001)$ and explained approximately $24 \%$ of variance in levels of happiness (Table 3). Five variables were significantly associated with happiness levels, with unmet psychological needs exhibiting the strongest effect $(\beta=-.38, p=.028)$, followed by unmet health care service needs $(\beta=-.30, p=.049)$, unmet information needs $(\beta=.29, p=.028)$, comorbidity $(\beta=-.18$, $p=.030)$, and gender $(\beta=-.16, p=.045)$. Lower levels of unmet psychological and health care needs, higher levels of unmet information needs, absence of any comorbid physical illness, and being male were predictive of higher levels of happiness.

Table 3 Multiple regression model for carer happiness (CarerQol-VAS)

\begin{tabular}{|c|c|c|c|c|c|c|c|c|c|}
\hline & $R^{2}$ & Adjusted $R^{2}$ & $\beta$ & $p$ & $t$ & $B$ & SE & CI $95 \%$ (B) & \\
\hline Model $^{\mathrm{a}}$ & $.298 * *$ & $.238^{* *}$ & & & & & & & \\
\hline $\begin{array}{l}\text { Gender } \\
\text { (Ref }^{b}: \text { male) }\end{array}$ & & & $-0.16^{*}$ & .045 & -2.02 & -0.76 & 0.38 & -1.51 & -0.02 \\
\hline Age & & & 0.13 & .184 & 1.33 & 0.02 & 0.02 & -0.01 & 0.05 \\
\hline $\begin{array}{l}\text { Employment status } \\
\text { (Ref: employed) }\end{array}$ & & & 0.04 & .664 & -0.43 & -0.16 & 0.38 & -0.91 & 0.58 \\
\hline $\begin{array}{l}\text { Comorbidity } \\
\text { (Ref: no medical condition) }\end{array}$ & & & $-0.18^{*}$ & .030 & -2.20 & -0.77 & 0.35 & -1.47 & -0.08 \\
\hline $\begin{array}{l}\text { Relationship } \\
\text { (Ref: married/living with) }\end{array}$ & & & 0.01 & .948 & -0.06 & -0.03 & 0.40 & -0.82 & 0.77 \\
\hline Financial impact & & & 0.02 & .808 & 0.24 & 0.04 & 0.16 & -0.35 & 0.27 \\
\hline Time spent caring & & & 0.04 & .571 & 0.57 & 0.00 & 0.01 & -0.01 & 0.02 \\
\hline Information needs & & & $0.29 *$ & .028 & 2.23 & 0.03 & 0.01 & 0.00 & 0.06 \\
\hline Health care needs & & & $-0.30^{*}$ & .049 & -1.99 & -0.03 & 0.02 & -0.06 & 0.00 \\
\hline Work and social needs & & & 0.00 & .992 & 0.01 & 0.00 & 0.02 & -0.04 & 0.04 \\
\hline Psychological needs & & & $-0.38^{*}$ & .028 & -2.22 & -0.04 & 0.02 & -0.07 & 0.01 \\
\hline
\end{tabular}

Statistical significance: ${ }^{*} p<<.001,{ }^{*} p<.05$

${ }^{\text {a }}$ For all continuous variables, higher scores indicate higher levels of the variable

${ }^{\mathrm{b}}$ Reference category for categorical variables 


\section{Discussion}

\section{HNC carer subjective burden}

While most HNC carers experienced fulfilment with their caring tasks, almost a half reported, at least to some extent, both mental and physical health problems. A few previous studies have reported that $\mathrm{HNC}$ carers experience significant deficits in psychological health compared to the general population $[13,32]$, and indeed, cancer carers have been reported to experience more distress and more reductions in quality of life than cancer patients themselves [10]. Nevertheless, the heterogeneity of measures used to assess $\mathrm{HNC}$ carer quality of life $[18,32]$ has hampered cross study comparisons and limited assessment to broad level findings. Similar to the measurement of quality of life in HNC patients [32], there appears to be no gold standard questionnaire used in practice. Future work should look towards standardising the measurement of HNC carer quality of life, or at a minimum, decreasing the number of instruments used, in order to increase the generalisability of the derived results. Less evidence is available on the physical health burden on cancer carers generally, or HNC carers specifically. Our results indicate that physical health problems are common, and that there would be value in further exploring the influences on these.

A degree of consensus exists in the literature across disease types with regard to the positive aspects associated with care (fulfilment and support) as measured by the CarerQol-7D [29, 33]. The extent, however, to which carers experience negative aspects of care appears to vary by disease. HNC carers in our study reported a higher financial burden $(29 \%$ reported at least some financial burden) than in previous studies of adult informal carers [28]: $12 \%$ with financial difficulties and carers of people with other non-cancer conditions (depression [34], $20 \%$; Duchenne muscular dystrophy [33], $17 \%$ ), but less than carers of children with autism [35]: $52 \%$. This may reflect an association between $\mathrm{HNC}$ and low socioeconomic status [36]. Also, HNC carers in our study reported fewer relationship problems with their care recipients than carers of people with other non-cancer conditions [28, 29, 34] possibly indicating a relatively strong bond between patient-carer dyads in HNC; however, comparison with other HNC carer populations is limited due to the dearth in application of the CarerQol in this area. The observed association is consistent with research in other cancer populations in Ireland [37] and could reflect cultural norms in Ireland.

\section{Subjective HNC carer burden associations}

Unmet healthcare service needs were significantly associated with carer burden. The importance of healthcare services to carers in our sample was reflected in the rankings of singleitem questions which relate to healthcare service needs including looking after the carers own health (ranked second of 45 potential unmet needs), addressing fears about the patient's mental and physical deterioration (fifth), accessing treatment information (seventh), and discussing concerns with doctors (ninth).

Carer unmet healthcare needs have been consistently reported throughout the general cancer literature $[6,10,24$, 25], and in the HNC-specific literature $[12,15]$. In a recent study, $39 \%$ of cancer carers of patients with various diagnoses and disease stages indicated dissatisfaction with the amount of time health care professionals spent on informing them and $30 \%$ were dissatisfied with their level of involvement in the patient's treatment or care [38]. In line with our findings, unmet needs in this domain have been associated with carer distress [10] and wellbeing [25] indicating the impact this can have on various aspects of quality of life.

Our findings on the importance of the information aspects of unmet healthcare needs may reflect the fact that decisions regarding cancer treatment and care are seldom made by the patients alone. Patients rely on their social networks and interpersonal relationships to inform decision-making [39]. This may especially be the case with $\mathrm{HNC}$ where the functional and social impairments among survivors [3,11], and their resulting care needs, are complex. This creates a complex environment for carers who invariably experience heightened healthcare needs which may be unmet, as evidenced here.

\section{HNC carer happiness associations}

On average, HNC carers reported reasonably high levels of happiness - comparable with population norms from the European Quality of Life Survey [40] — suggesting that caring for HNC survivors did not significantly impact on their wellbeing. This may be because, rather than decreasing happiness, caring may in fact increase happiness, especially if the time involved is less than $6 \mathrm{~h}$ a week [41]. Although our results did not indicate those spending less time caring were happier overall, a number of other associations emerged which yielded insight into the factors involved in this process.

Consistent with other research (e.g. [41]), we found that female carers of HNC survivors had lower levels of happiness than their male counterparts, a difference which cannot be accounted for by longer hours spent caring. While female carers did not report feeling more burdened by care, their lower level of happiness may reflect an underlying need for more psychological support $[4,16]$; we found that female carers in our sample reported higher psychological and emotional unmet needs than male carers. Similarly, while comorbidity did not influence carer burden, it did demonstrate a significant association with happiness, suggesting that those carers suffering from health complications are more likely to suffer deficits in quality of life, a finding echoed elsewhere $[29,37,41]$. This may be explained by the fact that those with 
comorbid conditions have a greater difficulty combining care with their daily activities [29]; however, it cannot be ruled out that lower happiness could be due to the comorbid condition itself, rather than the act of caring.

After adjusting for gender and comorbidity, the perceived unmet needs of carers also had a significant impact on happiness levels. The observed association between lower unmet psychological support needs and greater happiness is consistent with the finding that a range of unmet needs put cancer carers at risk of poor mental health [24]. Meeting psychological needs in particular is important for wellbeing, with psychological support desired in a significant number of both HNC survivors and carers [42]. In our sample, concern about cancer recurrence was the highest ranked individual unmet need; a concern which has been previously documented to negatively impact on quality of life among HNC carers [43] and general cancer carers [44]. Of the interventions that have currently been developed to address fear of cancer recurrence [45], almost none have addressed the concerns of carers on this issue. This highlights an important gap that requires future work.

Perhaps counter-intuitively, higher levels of unmet information needs were positively associated with happiness in our sample. One possible explanation for this is that happier carers are more predisposed to, or have a greater desire for, information. This may also be understood with reference to Norwood's [46] information needs pyramid, which describes the kinds of information that individuals seek at different levels. Perhaps less happy carers are at a lower level of information need and therefore tend to concentrate on information that satisfies an immediate need (e.g. coping information), while happier carers seek the higher level of 'helping information' requiring continuous refreshing and confirmation.

\section{Implications}

Since unmet healthcare service needs were associated with both carer burden and happiness, it is important for carer wellbeing that ways are found to better meet these needs. Longacre [47] noted that HNC carers suffering from higher objective burden (as measured by the Type of Care Index and the Hours of Care Index) prefer to receive information from health professionals as compared to carers with a lower objective burden. It follows that clearer routes by which carers can engage directly with health professionals would be beneficial. However, Longacre [47] also found that those with low objective burden are more likely to prefer seeking information from other sources, such as the internet, highlighting the need to provide alternate channels to access healthcare information.

To aid the transition from hospital to home care, access to transparent information on the various supports that the health care profession provide including speech and language therapy, dieticians, and oral rehabilitation [12, 39] should be provided to carers, as well as patients. This may not only reduce unmet healthcare service needs but also unmet information needs, potentially increasing many aspects of carer wellbeing (also [12].

\section{Strengths and limitations}

A core contribution of this study is our elucidation of the association between unmet supportive care needs and HNC carer subjective burden and happiness, after adjusting for carer characteristics. This represents an extension to the current $\mathrm{HNC}$ literature which tends to concentrate on patient factors and carer characteristics.

Our study also has a number of limitations. The cross sectional nature of the design means that the results are specific to one time point and claims of causality cannot be made. While the response rate was relatively high, we cannot exclude the possibility of potential non-response bias and that carer quality of life may be different across groups of non-respondents compared to respondents. It is also possible that associations between individual domains of burden may differ from those examined based on an aggregate burden score, but, the nature of the CarerQol instrument limited the investigation of these individual domains. The single item CarerQol-VAS used to measure carer happiness is not specific to cancer carers and may include aspects beyond those related directly to the caregiving experience. Also, as a single-item measure assessing a multidimensional construct, it is unclear which specific aspects are impaired by caring, an issue partially overcome by the use of the CarerQol-7D. Disease and treatment-related patient information has not been included in the analysis as the focus of the study was on carer-related factors. Finally, the internal reliability of the CarerQol-7D was somewhat low, likely due to incorporating less than ten items and the sample size. This may have led to some underestimation of correlations in the analysis.

\section{Conclusions}

Our results indicated that different aspects of carer characteristics and unmet needs were associated with carer burden and happiness. While carer burden in HNC may be reduced by addressing the unmet healthcare service needs of carers, happiness was associated with a wider range of characteristic, situational, and unmet need factors. Therefore, meeting a range of needs is important for maximising overall wellbeing among carers as well as recognising that particular groups may be more vulnerable to poorer quality of life - in particular female carers, and those with a pre-existing health condition.

Acknowledgments We would like to thank the health professionals involved in this project for facilitating the survivor survey and supporting 
the local ethics applications. We also appreciate the advice and helpful comments provided by Dr. Rachael Gooberman-Hill.

\section{Compliance with ethical standards}

Conflict of interest The authors declare that they have no competing interests.

Ethical approval All procedures performed in studies involving human participants were in accordance with the ethical standards of the institutional and/or national research committee and with the 1964 Helsinki declaration and its later amendments or comparable ethical standards.

Informed consent Informed consent was obtained from all individual participants included in the study.

Grant information Funding for this study was supplied by the Health Research Board (HRA/2009/262; HRA/2009/262/R).

\section{References}

1. Simard EP, Torre LA, Jemal A (2014) International trends in head and neck cancer incidence rates: differences by country, sex and anatomic site. Oral Oncol 50:387-403

2. Jemal A, Bray F, Center MM, Ferlay J, Ward E, Forman D (2011) Global cancer statistics. CA Cancer J Clin 61:69-90

3. Ross S, Mosher CE, Ronis-Tobin V, Hermele S, Ostroff JS (2010) Psychosocial adjustment of family caregivers of head and neck cancer survivors. Support Care Cancer 18:171-178

4. Baghi M, Wagenblast J, Hambek M, Radeloff A, Gstoettner W, Scherzed A, Spaenkuch B, Yuan J, Hornung S, Strebhardt K, Knecht R (2007) Demands on caring relatives of head and neck cancer patients. Laryngoscope 117:712-716

5. Stenberg U, Ruland CM, Miaskowski C (2010) Review of the literature on the effects of caring for a patient with cancer. Psychooncology 19:1013-1025

6. Kim Y, Kashy DA, Spillers RL, Evans TV (2010) Needs assessment of family caregivers of cancer survivors: 3 cohort comparisons. Psychooncology 19:573-582

7. Chen SC, Chiou SC, Yu CJ, Lee YH, Liao WY, Hsieh PY, Jhang SY, Lai YH (2016) The unmet supportive care needs - what advanced lung cancer patients' caregivers need and related factors. Support Care Cancer

8. Heckel L, Fennell KM, Reynolds J, Osborne RH, Chirgwin J, Botti M, Ashley DM, Livingston PM (2015) Unmet needs and depression among carers of people newly diagnosed with cancer. Eur J Cancer 51(14):2049-2057

9. Friðriksdóttir N, Saevarsdóttir T, Halfdánardóttir SÍ, Jónsdóttir A, Magnúsdóttir H, Olafsdóttir KL, Guðmundsdóttir G, Gunnarsdóttir S (2011) Family members of cancer patients: needs, quality of life and symptoms of anxiety and depression. Acta Oncol 50:252-258

10. Sklenarova H, Krumpelmann A, Haun MW, Friederich HC, Huber J, Thomas M, Winkler EC, Herzog W, Hartmann M (2015) When do we need to care about the caregiver? Supportive care needs, anxiety, and depression among informal caregivers of patients with cancer and cancer survivors. Cancer 121:1513-1519

11. Patterson JM, Rapley T, Carding PN, Wilson JA, McColl E (2013) Head and neck cancer and dysphagia; caring for carers. Psychooncology 22:1815-1820
12. Chen SC, Lai YH, Liao CT, Huang BS, Lin CY, Fan KH, Chang JT (2014) Unmet supportive care needs and characteristics of family caregivers of patients with oral cancer after surgery. Psychooncology 23:569-577

13. Goren A, Gilloteau I, Lees M, DaCosta Dibonaventura M (2014) Quantifying the burden of informal caregiving for patients with cancer in Europe. Support Care Cancer 22:1637-1646

14. Butow PN, Price MA, Bell ML, Webb PM, deFazio A, Australian Ovarian Cancer Study Group, Australian Ovarian Cancer Study Quality Of Life Study Investigators, Friedlander M. (2014) Caring for women with ovarian cancer in the last year of life: a longitudinal study of caregiver quality of life, distress and unmet needs. Gynecol Oncol 132: 690-697.

15. Chen SC, Tsai MC, Liu CL, Yu WP, Liao CT, Chang JT (2009) Support needs of patients with oral cancer and burden to their family caregivers. Cancer Nurs 32:473-481

16. Longacre ML, Ridge JA, Burtness BA, et al. (2012) Psychological functioning of caregivers for head and neck cancer patients. Oral Oncol 48:18-25

17. Kim Y, Given BA (2008) Quality of life of family caregivers of cancer survivors across the trajectory of the illness. Cancer 112(11 Suppl):2556-2568

18. Sterba KR, Zapka J, Cranos C, Laursen A, Day TA (2015) Quality of life in head and neck cancer patient-caregiver dyads: a systematic review. Cancer Nurs 39:238-250

19. Tay L, Kuykendall L, Diener E (2015) Satisfaction and happinessthe bright side of quality of life. In global handbook of quality of life. Netherlands, Springer

20. Pearce A, Timmons A, O'Sullivan E, Gallagher P, Gooberman-Hill R, Thomas AA, Molcho M, Butow P, Sharp L (2015) Long-term workforce participation patterns following head and neck cancer. J Cancer Surviv 9:30-39

21. Thomas AA, Timmons A, Molcho M, Pearce A, Gallagher P, Butow P, O'Sullivan E, Gooberman-Hill R, O'Neill C, Sharp L (2014) Quality of life in urban and rural settings: a study of head and neck cancer survivors. Oral Oncol 50:676-682

22. Sharp L, Carsin AE, Timmons A (2013) Associations between cancer-related financial stress and strain and psychological wellbeing among individuals living with cancer. Psychooncology 22: 745-755

23. Hanly P, Ceilleachair AO, Skally M, O'Leary E, Kapur K, Fitzpatrick P, Staines A, Sharp L (2013) How much does it cost to care for survivors of colorectal cancer? Caregiver's time, travel and out-of-pocket costs. Support Care Cancer 21:2583-2592

24. Girgis A, Lambert S, Lecathelinais C (2011) The supportive care needs survey for partners and caregivers of cancer survivors: development and psychometric evaluation. Psychooncology 20:387-393

25. Girgis A, Lambert S, Johnson C, Waller A, Currow D (2013) Physical, psychosocial, relationship, and economic burden of caring for people with cancer: a review. J Oncol Pract 9:197-202

26. Brouwer WB, van Exel NJ, van Gorp B, Redekop WK (2006) The CarerQol instrument: a new instrument to measure care-related quality of life of informal caregivers for use in economic evaluations. Qual Life Res 15:1005-1021

27. Hoefman RJ, Van Exel NJA, Brouwer WBF (2013) iMTA valuation of informal care questionnaire. http://www.bmg.eur.nl/fileadmin/ ASSETS/bmg/english/iMTA/iVICQ/Version_1.1/iVICQ_UK_ version_1.1.pdf. Accessed 29th Jan 2015

28. Hoefman RJ, van Exel NJ, Foets M, Brouwer WB (2011) Sustained informal care: the feasibility, construct validity and test-retest reliability of the CarerQol-instrument to measure the impact of informal care in long-term care. Aging Ment Health 15:1018-1027

29. Hoefman RJ, van Exel J, Brouwer WB (2013) Measuring the impact of caregiving on informal carers: a construct validation study of the CarerQol instrument. Health Qual Life Outcomes 11(173). doi:10.1186/1477-7525-11-173 
30. Lutomski JE, van Exel NJ, Kempen GI, Moll van Charante EP, den Elzen WP, Jansen AP, Krabbe PF, Steunenberg B, Steyerberg EW, Olde Rikkert MG, Melis RJ (2015) Validation of the care-related quality of life instrument in different study settings: findings from the older persons and informal caregivers survey minimum DataSet (TOPICS-MDS). Qual Life Res 24:1281-1293

31. Tabachnik BG, Fidell LS (2014) Using multivariate statistics, 7th edn. Boston, Pearson Education

32. Ojo B, Genden EM, Teng MS, Milbury K, Misiukiewicz KJ, Badr H (2012) A systematic review of head and neck cancer quality of life assessment instruments. Oral Oncol 48:923-937

33. Pangalila RF, van den Bos GA, Stam HJ, van Exel NJ, Brouwer WB, Roebroeck ME (2012) Subjective caregiver burden of parents of adults with Duchenne muscular dystrophy. Disabil Rehabil 34:988-996

34. Stjernsward S, Hansson L (2014) A web-based supportive intervention for families living with depression: content analysis and formative evaluation. JMIR Res Protoc 3:e8

35. Hoefman RJ, Payakachat N, van Exel J, Kuhlthau K, Kovacs E, Pyne J, Tilford JM (2014) Caring for a child with autism Spectrum disorder and parents' quality of life: application of the CarerQol. J Autism Dev Disord 44:1933-1945

36. Andersen ZJ, Lassen CF, Clemmensen IH (2008) Social inequality and incidence of and survival from cancers of the mouth, pharynx and larynx in a population-based study in Denmark, 1994-2003. Eur J Cancer 44:1950-1961

37. Hanly P, Maguire R, Hyland P, Sharp L (2015) Examining the role of subjective and objective burden in carer health-related quality of life: the case of colorectal cancer. Support Care Cancer 23:1941-1949

38. Lund L, Ross L, Petersen MA, Groenvold M (2015) The interaction between informal cancer caregivers and health care professionals: a survey of caregivers' experiences of problems and unmet needs. Support Care Cancer 23:1719-1733

39. Adams E, Boulton M, Watson E (2009) The information needs of partners and family members of cancer patients: a systematic literature review. Patient Educ Couns 77:179-186

40. European Quality of Life Surveys. European Quality of Life Survey (2012). http://www.eurofound.europa.eu/surveys/europeanquality-of-life-surveys-eqls/european-quality-of-life-survey-2012. Accessed 10 April 2015.

41. van Campen C, de Boer AH, Iedema J (2013) Are informal caregivers less happy than noncaregivers? Happiness and the intensity of caregiving in combination with paid and voluntary work. Scand J Caring Sci 27:44-50

42. Richardson AE, Morton R, Broadbent E (2015) Psychological support needs of patients with head and neck cancer and their caregivers: a qualitative study. Psychol Health 30:1288-1305

43. Hodges LJ, Humphris GM (2009) Fear of recurrence and psychological distress in head and neck cancer patients and their carers. Psychooncology 18:841-848

44. Mellon S, Kershaw TS, Northouse LL, Freeman-Gibb L (2007) A family-based model to predict fear of recurrence for cancer survivors and their caregivers. Psychooncology 16:214-223

45. Simard S, Thewes B, Humphris G, Dixon M, Hayden C, Mireskandari S, Ozakinci G (2013) Fear of cancer recurrence in adult cancer survivors: a systematic review of quantitative studies. J Cancer Surviv 7:300-322

46. Norwood G. Maslow's hierarchy of needs. The Truth Vectors (Part I). http://www.deepermind.com/20maslow.htm. Accessed Oct 2015

47. Longacre ML (2013) Cancer caregivers information needs and resource preferences. J Cancer Educ 28:297-305 